\title{
Cecil Charles, traductora de Martí
}

$\mathrm{H}^{\mathrm{L}}$ interés por la obra de Martí ha aumentado enormereciente celebración del centenario del nacimiento de Martí. Ahora tenemos a mano muchos estudios biográficos y bibliográficos así como ensayos de crítica literaria. A pesar del número de tales estudios, no se han estudiado todavía las traducciones de su obra. En vista de la importancia de Martí, nos sorprende que no exista ningún estudio de las traducciones al inglés, al francés o al portugués. Como un comienzo a tal trabajo presento aquí unos datos acerca de Cecil Charles que tradujo al inglés casi la mitad de los Versos sencillos. Estas traducciones son las primeras y con una sola excepción las únicas en inglés. 1

Escasa es la mención de Cecil Charles entre los escritores que se han dedicado a estudiar la obra martiana. Andrés Iduarte y Manuel Pedro González mencionan las traducciones en sus respectivas bibliografías; Gonzalo de Quesada y Rafael Esténger le llaman a Cecil Charles "joven poeta americana y ...alumna de Martí."2 Hasta su nombre sufre del olvido y Federico de Onís la llama Celia Charles. ${ }^{3}$ En fin, no se ha prestado ninguna atención a esta poetisa norteamericana que

1 Roy Temple House hizo una versión al inglés de "Cultivo una rosa blanca" titulada "Dialogue", Poetry, LXV (1945), pág. 309.

2 Gonzalo de Quesada, Martí, Hombre (La Habana, 1940), pág. 207.

3 José Martí, The Americas of José Martí (selected writings translated from the Spanish by José de Onis with an introduction by Federico de Onís) (New York, 1953), pág. xi. 
reconoció el valor de Martí y tradujo por primera vez su poesía. Un ejemplo de esta falta de atención se ve en una sugerencia del señor Esténger de que había "una entrega amorosa" 4 por parte de ella, tal sugerencia basada, sin duda, en el título del libro que contiene sus traducciones: Tuya, Other Verses and Translations from José Martí. El título se refiere a un ramito de un árbol conífero y fragante que da nombre al primer poema de la colección, pero si no se lee el libro, claro que se puede entregar uno al error.

También los libros de Cecil Charles yacen olvidados. En el catálogo de la Biblioteca del Congreso en Washington se encuentran los siguientes títulos bajo su nombre: Costa Rica and Her Future, traducción del francés de Paul Biolley, 1889; Honduras, Land of Great Depths, ${ }^{6}$ 1890; Tuya, Other Verses and Translations from José Martí,7 1898 y Miss Sylvester's Marriage, 81903.

En Honduras, que es en gran parte un libro autobiográfico, hallamos primero algunos datos que nos llevaron en busca de otros al periódico Honduras-Progress, publicado en Tegucigalpa durante los años 1888-1890, la misma época de la que trata Cecil Charles en este libro. En este periódico aparecen varias noticias de las que se desprende que Cecil Charles es un pseudónimo y que pertenece a una mujer, a pesar de que la única reseña del libro se refiere al autor como $\mathrm{Mr}$. Charles. En septiembre de 1888 apareció en el mismo perió-

4 Rafael Esténger, Vida de Martí (Santiago de Chile, 1936), pág. 79.

5 (New York, 1898). De aquí en adelante doy las páginas en el texto.

- Este libro es la relación de un viaje desde la costa occidental de Honduras hasta San Juancito. Contiene datos sobre la industria minera del país y estadísticas generales sobre la agricultura y la economía de Honduras sacadas en gran parte del periódico Honduras-Progress. Además, incluye el relato de su viaje desde Tegucigalpa a Puerto Cortés a lo largo de la propuesta ruta de un ferrocarril nacional. El libro se escribió como guía para turistas.

7 Además de las traducciones, el volumen contiene el poema "Tuya" y otras veinte y seis poesías inclusive una paráfrasis de Walt Whitman. De éstas, nueve tienen algo que ver con las tierras y productos tropicales o la independencia de Cuba.

8 En esta novela se ve claramente su interés por lo hispanoamericano: una joven de sangre venezolana se casa en Nueva York con un aventureto paraguayo, matrimonio que termina en desilusión y divorcio. La autora emplea palabras y expresiones en español para dar sabor al lenguaje y hace que el paraguayo hable un inglés básbaro y poco convincẹnte, 
dico una nota sobre Mrs. Lily Tyner de Chicago que estaba en la capital de viaje en mula a Puerto Cortés donde pensaba embarcarse para Nueva Orleans. La parte final del libro Honduras consiste en un relato de ese viaje en mula hecho por la autora desde Tegucigalpa hasta Puerto Cortés. Llegó a la costa a principios de octubre y, sin duda, se embarcó en el vapor Macgregor el doce de ese mes llegando a Nueva Orleans el diez y seis. De aquí dedujimos que Cecil Charles y Mrs. Lily Tyner son la misma persona. Otras noticias en el periódico citado revelan que ella era la esposa de Michael Paul Tyner de la compañía minera Rosario en el pueblo de San Juancito en Honduras.

Persiguiendo noticias de sociedad, que a tal extremo nos reduce la falta de estudios, encontramos un artículo en el $\mathrm{New}$ York Times del veinte y tres de febrero de 1887 el cual se refiere a un divorcio pedido por una señora Mary Tyner de su esposo, Michael Paul Tyner. La esposa había nombrado a Lily Curry cómplice por haber enajenado el afecto del marido cuando éste se había entrevistado con la señorita Curry, siendo él reportero del New York World. En su defensa Tyner explicó al juez que él y Lily Curry se habían casado hacía diez años, siendo los dos muy jóvenes, y que sus padres los habían separado y habían llevado a Lily al Oeste, y que más tarde había llegado a creer que ella había muerto. Luego se había casado con Mary. Sin embargo, al encontrarse de nuevo Tyner y Lily, se había reanudado su amor. El juez no creyó tal cuento y otorgó el divorcio en agosto del mismo año, un mes después de la salida de Lily para San Juancito, según la fecha dada por ella en su libro. No sabemos si el señor Tyner la acompañó en ese viaje porque, aunque menciona un compañero de viaje, no indica quién era. En el libro describe la manera de celebrarse las bodas de una americana en San Juancito y sospechamos que se casaron después de su llegada a Honduras.

Al buscar informes sobre Lily Curry encontramos dos libros suyos publicados en 1886 y 1887: A Bohemian Tragedy ${ }^{9}$

9 "a spicy novel of New York life" según el anuncio del libro. Esta novela trata de un amorío típico de las novelas populares de la época. 
y Drops of Blood.10 También hay una versión al inglés de un poema largo del Dr. Hermann Krasser llamado AntiSyllabus.11 Según una noticia en la contratapa de su novela, Lily Curry era una eminente dama de letras de Nueva York que escribía novelas, cuentos y artículos para revistas.

A los tres meses de su salida de Puerto Cortés, vió la luz un artículo suyo en el Honduras-Progress del veinte y cuatro de enero de 1889 enviado de San José de Costa Rica en el cual Lily Tyner describe el terremoto que había sufrido aquella ciudad. Otro artículo, también escrito en San José, se publicó en el mismo periódico el catorce de febrero. $\mathrm{Pa}$ rece que se quedó en la capital costarricense hasta mediados del año 1890 porque se publicaron cuatro poemas suyos en el Times-Democrat de Nueva Orleans entre enero y septiembre de 1890. En febrero y noviembre aparecieron artículos suyos sobre Costa Rica en Frank Leslie's Popular Monthly, una revista neoyorkina. Todos los poemas y artículos menos el último están fechados en San José.

Por el contenido de la poesía publicada en la sección literaria del Times-Democrat, que parece autobiografía, podemos reconstruir en parte lo que le pasó con el señor Tyner: un casamiento feliz por unos meses, que más tarde llegó a ser insoportable para ella. Por eso se separó de él y se fué a los Estados Unidos y luego a San José. El poemita "Two Names" no puede sino referirse a Michael Paul:

Always whenever henceforth I shall find Staring me blackly in the face two names, The two that you before your surname signed...

En el resto del poema se queja del hombre a quien antes había amado tanto y que la había desilusionado. Más tarde

10 Es una colección de catorce cuentos de episodios morbosos, caracterizados por asesinatos, suicidios, víctimas de la tisis y el amor fracasado. Todos tienen un alto sentido de la moral y la virtud femenina. En general, los cuentos están bien escritos: mezcla de narración y diálogo, énfasis sobre la acción más bien que la delineación de los caracteres.

I1 Este poema apareció en 1886 en un folleto publicado por un partido político, sin duda socialista-obrero, junto con un artículo de John Brophy sobre la muerte de Tom Strang y la conferencia de Shelley a los obreros ingleses, Men of Labor. 
escribió otro, "To a Dead Man," en que perdona al que habia sido tan cruel. Estos poemas son las primeras obras que publica con el pseudónimo Cecil Charles.

Es probable que volviera Cecil Charles a Nueva York en el otoño de 1890 porque el libro Honduras fué publicado a fines de ese año, y además sabemos que ella asistió a las clases que dictó José Martí en Nueva York entre 1889 y 1891. Después de la muerte de Martí, tradujo casi la mitad de los Versos sencillos y publicó estas traducciones en una colección de sus propios versos. En 1903 apareció su última novela, Miss Sylvester's Marriage. Después ya no se puede averiguar nada de Cecil Charles. Ninguna historia de la literatura americana la menciona. Pero si su propia obra no vale mucho, sus traducciones de Martí le ganan un lugar de cierta importancia en la historia puesto que son las primeras traducciones de la poesía de Martí al inglés.

Ya hemos dicho que Cecil Charles fué estudiante de Martí, y como en todos los que tuvieron contacto personal con el gran maestro que fué Martí, nació en ella un afecto y un aprecio duraderos. Ese afecto, además de su interés por las tierras latinoamericanas, nos explica el interés que mostró por Martí y su poesía de la que tradujo diez y siete poemas y fragmentos de otros tres. Cierto acercamiento de sus dos espíritus se puede notar en los Versos sencillos que escogió Cecil Charles para traducir. Al examinar esta selección, se ve que son los poemas que tratan de la naturaleza, la hermo. sura de las mujeres, la amistad y el amor, la manera de morir y la actitud anti-esclavista y anti-tirana. Los Versos de estilo modernista y de pensamiento más profundo se dejan por falta de interés o porque encuentra difícil la traducción dentro de las normas convencionales de la época.

El convencionalismo poético de exagerar la importancia de la rima es, sin duda, el defecto principal de las traducciones puesto que, dadas las diferencias inherentes a los dos idiomas, algo tiene que sacrificarse para mantener una rima exacta como la mantiene Cecil Charles. Citamos aquí sólo dos ejemplos de estrofas que muestran el efecto de tanta exactitud en la rima y que resultan poco poéticas en inglés: 
Once, too, my heart went leaping

With a joy of joys tremendous-

When the jailer read me weeping,

The sentence of death tremendous. (p. 62)

o bien ésta:

I, who live though my heart hath died,

Am great discoverer as you see,

Since yester-eve I certified

Love's unfailing remedy. (p. 72)

Todos los Versos sencillos de Martí son octosílabos y con la excepción de tres poemas están todos escritos en cuartetas con una variedad de rimas, inclusive la monorrima y el verso libre. De estas tres excepciones la única que tradujo Cecil Charles es la que tiene la forma más libre en español, y a nuestro parecer la traducción de ésta es la más exacta de todas. Esto se debe, sin duda, a la ausencia de una rima fija a la cual la traductora está demasiado atenta en otros poemas. Nótense el ritmo y el tono heroico-marcial así como la fidelidad a las ideas en la traducción del poema XLV:

¡Hablo con ellos, de noche!

Están en fila: paseo

Entre las filas: Iloroso

Me abrazo a un mármol: "Oh mármol,

Dicen que beben tus hijos

$\mathrm{Su}$ propia sangre en las copas

Venenosas de sus dueños!

iQue hablan la lengua podrida

De sus rufianes! ¿Que comen

Juntos el pan del oprobio,

En la mesa ensangrentada!

¡Que pierden en lengua inútil

El último fuego! ¡Dicen,

Oh mármol, mármol dormido,

Que ya se ha muerto tu raza!

Nigthly

Speak I with these in their cloisters:

They are in file and I wander

Threading the ranks till a-weeping 


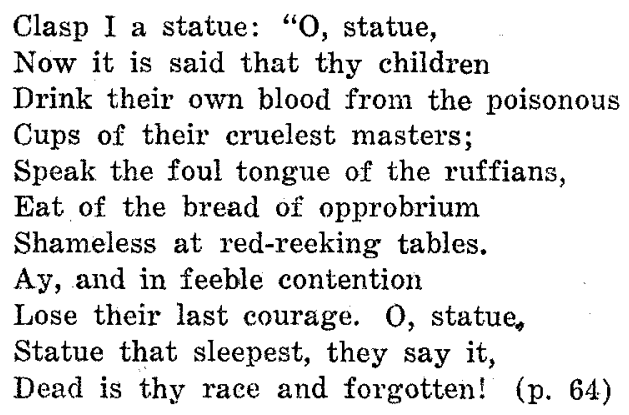

La versión es muy buena; se mantienen las imágenes, el tono y la emoción. Claro está que hay una o dos frases poco eufónicas pero las ideas se reproducen con exactitud y la expresión poética es por lo general muy superior a la de las otras traducciones.

Por lo común, Cecil Charles ha tenido cuidado de no perder las imágenes poéticas aunque hay ciertos cambios y pérdidas que hacen más débiles o menos poéticas las estrofas como, por ejemplo, en la pérdida de la antítesis de estas líneas:

No nace en el torvo suelo From the sterile soil no ray Ni una viola, ni una espiga... Of hope in a blade of green... (p. 66)

También en la métrica se ve el sacrificio a la rima aunque la traductora trata de mantener el mismo metro de Martí -el verso octosílabo. Ella emplea versos de tres, de tres y medio y de cuatro pies (de seis hasta diez sílabas), pies mixtos, y aún los emplea en un solo verso. Esta esclavitud a la rima hace que la traductora emplee palabras inglesas que suenan mal por no ser poéticas —que sacrifique la exactitud del sentido, que añada ideas inútiles y que destruya a veces el tono del poema. Por el contrario, hay unas versiones muy buenas como la del Verso $X L V$, que ya hemos visto, donde mantiene el ritmo dactílico de ocho sílabas igual a la versión original, resultando una traducción mucho más fiel.

Al estudiar la fidelidad a las ideas, podemos hallar en casi todas las estrofas algo que quita valor al poema, pero, por lo general, ella es bastante fiel a la idea principal del 
poema, sacrificando o sustituyendo sólo las ideas secundarias. A pesar de los varios defectos ya citados, muchos de los cuales resultan del convencionalismo de fines de siglo, las traducciones merecen estudio y un público más amplio. Hay estrofas muy bien hechas en las que la musicalidad del ritmo, las imágenes poéticas y la exactitud del sentido se mantienen en la versión inglesa, como en el poema que todos conocen, "Cultivo una rosa blanca":

I've a white rose growing sweetly,

Through every day in the year,

For the friend who comes sincere

With his handclasp warm and friendly.

And for the cruel who blindly

Would tear my heart till it bleed,

Thistle nor hateful weed,

But the white rose growing sweetly. (p. 73)

EUGENE C. SNEARY, Universidad de Tulane. 